Mag. Patrick

Vesel

Merkurd.d.

\title{
IZOBRAŽEVALNI MENEDŽMENT
}

\section{Pomen notranjega trženja pri ustvarjanju in vzgajanju odnosov z zaposlenimi}

\section{POVZETEK}

Termin notranjega trženja je bil izpeljan iz pojmovanja t. i. notranjega trga zaposlenih in potreb tržnikov po tem, da najprej na strani zaposlenih zagotovijo razumevanje trženjskih programov, ki so namenjeni doseganju porabnikov. Gre torej za aplikacijo trženjskega načina razmišljanja na področje izobraževalnega menedžmenta zaposlenih. Pri uspešni implementaciji omenjenega gre za povezanost vrhnjega menedžmenta, trženjske funkcije in oddelka za ravnanje s človeškimi viri. Notranje trženje tako funkcionira kot holistično upravljan proces, ki predstavlja način ozirona filozofijo upravljanja pri konuniciranju, usposabljanju, izobraževanju in inforniranju, motiviranju in razvoju ter pridobivanju, zaposlovanju in zadržanju zaposlenih. Pri tem velja prenos pristojnosti na podrejene za ključno komponento notranjega trženja, $v$ okviru katerega je zaradi dodatnih odgovornosti zaposlenih pomembna vloga izobraževalnega menedžmenta $v$ luči vzgajanja servilne in $h$ kupcu naravnane organizacijske kulture. Navkljub četrt stoletja dolgi zgodovini razvoja pa sicer sam koncept še ne uživa vsesplošne razpoznavnosti in razumevanja v svetu menedžmenta, saj naj bi bil ves čas naprednejši od okolja, v katerem se (je) nahaja(l).

Ključne besede: notranje trženje, odnosi, ravnanje s človeškimi viri, izobraževanje in usposabljanje, zaposleni

\footnotetext{
$\mathrm{M}$ etoda, ki se najpogosteje omenja $\mathrm{v}$ zvezi $z$ ustvarjanjem odnosov z zaposlenimi, je notranje trženje. Njen osnovni namen je $v$ osredotočenosti na zaposlcne $v$ povezavi $z$ uspešno izvedbo storitve za kupca (BroadyPreston, Steel, 2002, str. 294). že v uvodnem delu velja poudariti, da so si sicer številni avtorji (npr. Ahmed in Rafiq, 2002, str. 3; Rafiq in Ahmed, 2000, str. 449-500; Ballantyne, 2000, str. 274, in 2003, str. 1242; Papasolomou-Doukakis in Kitchen, 2004, str. 421; Peck idr., 1999, str. 323; Lings, 2000, str. 28)
}

enotnega mnenja, ko pravijo, da ne obstaja neka enopomenska definicija, ki bi natančneje in operativno pojasnjevala omenjeni koncept. Kang, James in Alexandris (2002, str. 278 in 280) tako ponujajo prikaz nekaterih definicij notranjega trženja, kar prikazuje tabela 1 . V zvezi s tem povedo, da gre za pomemben pristop pri vzgajanju servilne in $h$ kupcu naravnane organizacijske kulture.

Začetki razmišljanja o notranjem trženju segajo v začetek osemdesetih, ko so Berry idr. predlagali koncept notranjega trženja kot 


\section{Avtor}

Berry (1984)

Johnson et al. (1986)

Kotler in Armstrong (1991)

Bekkers in Van Hasstrecht (1993)

Ballantyne et al. (1995)

George in Grönroos (1999)

\section{Defin $\mathbf{c}$ ja}

Dojemanje zaposlenih kot notranjih kupcev, dojemanje delovnih mest kot notranji proizvodov in nato ob zasledovanju organizacijskih ciljev prizadevanje k ponudbi takšnih delovnih mest, ki zadovoljujejo potrebe in zahteve teh notranjih kupcev.

Prizadevanje storitvenih podjetij $\mathrm{k}$ jasnenu posredovanju in razumevanju korporativnega poslanstva in ciljev s strani vseh $v$ organizaciji s pomočjo usposabljanja, motiviranja in ocenjevanja doseganja želenih ciljev.

Gradnja usmerjenosti h kupcu med zaposlenimi z usposabljanjem in motiviranjem osebja, ki ima neposredni stik $s$ kupci, in osebja, ki nima neposrednega stika s kupci, da deluje kot team.

Katerakoli oblika tř̌cnja znotraj organizacije, ki usmerja pozornost zaposlenih na tiste notranje aktivnosti, $k i$ se morajo spremeniti, da bi povečali učinek na trgu.

Notranje trženje se nanaša na ptoces ustvarjanja tržnih pogojev znotraj organizacije, ki zagotavljajo, da so potrebe in zahteve notranjih kupcev dosežene.

Notranji trg zaposlenih je $v$ smeri servilnosti in usmerjenosti h kupcu najbolje motiviran $z$ aktivnim pristopom, podobnim trženju, pri čemer so uporabljene metode, podobne trženjskim.

Vir: Kang, James in Alexandris, 2002, str. 280

rešitev za problem zagotavljanja stalne visoke kakovosti izvajanja storitev (Rafiq in Ahmed, 2000, str. 449). V povezavi z zametki notranjega trženja se poleg Berryja pogosto omenja tudi Grönroos (npr. Berry, 2000, str. 161; Frost in Kumar, 2000, str. 359; Kang, James in Alexandris, 2002, str. 279), ki je poleg Gummesona avtor povezovanja notranjega trženja $s$ trženjem, temelječim na odnosih (Frost in Kumar, 2000, str. 359).

Navkljub četrt stoletja dolgi zgodovini razvoja sam koncept še ne uživa vsesplošne razpoznavnosti in razumevanja $v$ svetu menedžmenta (A hmed in Rafiq, 2002, str. IX; Sargeant in Asif, 1998, str. 77), čeprav na notranje trženje lahko gledamo tudi kot na podaljšano roko komunikacije in odnosa do zaposlenih s strani menedžmenta (Davis, 2001, str. 130). Glavni razlog za takšno stanje je po mnenju
Ahmeda in Rafiqa (2002, str. IX) $v$ tem, da je bil sam koncept ves čas naprednejši od ob dobja, v katerem se je nahajal.

\section{KONCEPTUALNA OPREDELITEV NOTRANJEGA TRŽENJA}

Termin notranjega trženja je prvenstveno iz peljan iz pojmovanja $t$. i. notranjega trga za poslenih in potreb tržnikov po tem, da najpre na strani zaposlenih zagotovijo razumevanjs trženjskih programov, ki so namenjeni pora bniku (Grönroos, 2001, str. 332). Strategij; notranjega trženja namreč usmerja aktivnost znotraj organizacije s podobnim ciljem ko »zunanja« trženjska strategija; slednja pomag; tržnikom doseči porabnika zunaj organizaci je, prva pa je s tem, ko uravnava sodelovanjı 
med posamezniki, oddelki in enotami znotraj neke organizacije, usmerjena $k$ doseganju t. i. notranjih kupcev (Bowen, 1996, v Nickels in Wood, 1997, str. 46).

Pri tem je seveda pomembna moč trženjske funkcije znotraj neke organizacije, ki mora biti dovolj izrazita, da $z$ usmerjenostjo $h$ kupcu vpliva tudi na ostale oddelke (Flipo,

Notranje trženje ima funkcijo navduševanja zaposlenih za prodajo izde $k a$ in storitev zunanjim kupcem.
1986, str. 6). Kotler (1972, str. 50) na primer v zvezi s tem $v$ enem izmed svojih zgodnejših prispevkov ugotavlja, da trženje običajno povzroča odziv z neprisilnimi elementi - lahko bi torej rekli, da tudi s svojo izrazitostjo. Strategija notranjega trženja mora tako poleg že omenjenega med t. i. "tržniki, zaposlenimi za polovični delovni čas «', ustvarjati navdih, konsistentno vedenje in spoštovanje do splošne trženjske strategije. Nenazadnje, notranje trženje izraža moč "tržnikov, zaposlenih za polni delovni čas«, ki jo uporabljajo pri vplivanju na »tržnike, zaposlene za polovični delovni čas za dosego ciljev zunanje trženjske strategije, nasprotno pa ravno vpliv zadnjih na prispevek $k$ ciljem zunanje strategije izraža moč prvih (Flipo, 1986, str. 8 in 13).

Poudarki notranjega trženja so sicer močneje prisotni na področju trženja storitev (Berry, 2000 , str. 161), sama ideja pa se razširja tudi na ostala področja (Peck et al., 1999, str. 312; Rafiq in Ahmed, 2000, str. 453). Ker je sama storitev nemalokrat posledica same izvedbe s strani zaposlenih (Вегту, 2000, str. 161), je zato storitev lahko kakovostna samo toliko, kot so v njeni izvedbi kakovostni ljudje, ki jo izvajajo. Če torej ljudje, ki izvajajo storitev, ne dosežejo kupčevih pričakovanj, potem jih prav tako ne doseže tudi storitcv (Berry in Parasuraman, 1991, str. 151 in 171). Podobno razmišlja tudi Judd (2003, str. 1302), ko pravi, da so zaposleni v organizaciji lahko močan element razlikovanja organizacije od konkurentov s ciljem ustvarjanja konkurenčne prednosti in vrednosti za kupca. Foster in Cadogan (2000, str. 186) pa s tem, ko menita, da je ravno odnos, ki nastaja med prodajnim osebjem in kupcem, ključnega pomena pri celotni učinkovitosti trženjskih odnosov neke organizacije, poudarjata pomen »tržnikov, za polovični delovni čas « $v$ samem konceptu trženjskih odnosov.

Zato je ključnega pomena, da se organizacija zaveda, da če hoče biti uspešna pri izvajanju trženja storitev, mora biti uspešna tudi pri izvajanju notranjega trženja, saj je to orodje za privabljanje, razvoj, motivacijo in zadržanje? kvalificiranih zaposlenih s pomočjo potreb zadovoljujočih se delovnih mest (Berry in Parasuraman, 1991, str. 151 in 171).

\section{RAZVOI IN EVOLUCIJA KONCEPTA NOTRANJEGA TRŽENJA}

Sam koncept oziroma ideja notranjega trženja ni pravzaprav nič novega (Sargeant in Asif, 1998, str. 67) - tisto, kar je novo, je poudarjanje trženjskega pristopa (Varey in Lewis, 1999, str. 926). Sicer je moč povzeti, da je notranje trženje doživelo tri razvojne stopnje, pri čemer je takšno pojmovanje notranjega trženja, kot ga opisujeta Berry in Parasuraman (1991, str. 151 in 171), po mnenju Ahmeda in Rafiga (2002, str. 4-9)

Prva stopnja v razvoju in evoluciji koncepta. Zanjo je značilna predpostavka, da so za organizacijo - če želi imeti zadovoljne kupce - potrebni zadovoljni zaposleni. Zaposlene pa je moč zadovoljiti tako, da so delovna mesta oblikovana kar najbolj $v$ skladu $z$ njihovimi potrebami.

$\mathrm{Z}$ vidika organizacij gre torej za izjemno kompleksno situacijo, ki na eni strani predstavlja zahtevne porabnike, ki jim morajo ustreči zaposleni, na drugi strani pa prikazuje zaposlene, ki imajo visoka pričakovanja $v$ 
Kot vidimo iz Berryeve definicije $v$ tabeli 1 , je torej poudarek na tem, da je potrebe zaposlenih moč zadovoljiti $z$ delovnimi mesti, ki naj bi v očeh zaposlenih dejansko predstavljala neke vrste izdelek. Težava s takšnim pojmovanjem notranjega trženja je po mnenju Abmeda in Rafiqa (2002, str. 5) v tem, [1] da »izdelek«, ki je prodan zaposlenim, ni nujno želen s strani zaposlenih in lahko predstavlja celo negativno koristnost, [2] zaposleni nimajo vedno svobodne možnosti izbire »izdelka«, [3] zaradi pogodbene narave zaposlenosti so zaposleni lahko tudi prisiljeni $v$ izbiro »izdelka«, ki ga dejansko morda sploh ne želijo, [4] finančni stroški zadovoljnih zaposlenih so lahko zelo visoki in, [5] nenazadnje, pojmovanje zaposlenih kot kupcev poraja vprašanje o tem, ali nimajo nemara potrebe zunanjih kupcev prednosti pred potrebami zaposlenih.

zvezi $\mathrm{z}$ delovnim mestom kot virom samoaktualizacije in osebnega razvoja.

Druga stopnja označuje razmišljanje Grönroosa (Ahmed in Rafic, 2002, str. 6). Izhodišče ideje se kaže $v$ tem, da morajo biti tisti zaposleni, ki so $v$ dejanskem stiku s porabnikom $\checkmark$ okviru interakcijskega trženja, prodajno in porabniško naravnani. Predstavljeno stališče prikazuje Georgova in Grönroosova definicija (glej tabelo 1). Glavna razlika med Berryjevim in Gronroosovim pojmovanjem je $v$ tem, da $v$ primeru slednjega zaposleni niso pojmovani kot kupci. Grönroosovo pojmovanje se tako osredotoča predvsem $\mathrm{k}$ orientiranosti zaposlenih v smeri proti kupcu, kar je doseženo $s$ procesom vplivanja na zaposlene in ne s procesom zadovoljevanja njihovih potreb, kot je to $v$ Berryjevem primeru (Ahmed in Rafiq, 2002, str. 6-7).

Tretja stopnja pa je zaznamovana s tem, ko so številni avtorji spoznali, da je lahko vloga notranjega trženja dejansko orodje za implementacijo strategij. Winter (1985) (v Ahmed in Rafiq, 2002, str. 7) je eden izmed prvih avtorjev, $\mathrm{ki}$ je poudarjal omenjeno vlogo, pojmuje jo kot "povezovanje, izobraževanje in motiviranje zaposlenih v smeri institucionalnih ciljev procesov, s činer zaposleni ne razumevajo in prepoznavajo samo vrednosti programa, pač pa tudi svoje mesto znotraj tega.« Poudarek je torej na medfunkcijski koordinaciji in implementaciji.
V splošnem si vsi trije pristopi delijo podobno osnovo: če obstaja cilj po učinkovitejši implementaciji strategij, potem obstajata potrebi po presežku medfunkcijskih sporov in boljši notranji komunikaciji. Notranje trženje je tako pojmovano kot mehanizem za zmanjšsevanje medoddelčnih in medfunkcijskih trenj ter orodje za preseganje upornosti proti spremembam (Ahmed in Rafiq, 2002, str. 7-9). Uvajanje sprememb v organizacijah je po mnenju Druckerja (1992, str. 406) obvezno, če želijo organizacije $v$ času vedno večjih zahtev $s$ strani porabnikov na eni strani ter vedno večjih zavedanj pravic zaposlenih na drugi, učinkoviteje konkurirati na trgu. Ahmed in Rafiq (2002, str. 9-10) kot odgovor na različne faze razvoja notranjega trženja ponujata definicijo, ki po njunem mnenju združuje Vloga notranjega trženja se odvija predvsem skozi izobraževanje in motiviranje zaposlenih v smeri ciljev organizacije. njuno ter Grönroosovo pojmovanje omenjenega; pravita, da je »notranje trženje načrtovan trud, ki uporablja pristope, podobne trženjskim, usmerjene $\mathrm{k}$ motivaciji zaposlenih za implementacijo in integracijo organizacijskih strategij na način usmerjenosti h kupcu.«Po njunem mnenju tako odpravljata Grönroosovo pomanjkljivost, ki naj bi bila $v$ tem, da ne poudarja medfunkcijske koordinacije.

$S$ tem pogledom se sicer ne strinjam, saj Grönroos (2001, str. 334) v enem izmed svo- 
jih novejših spoznanj pove, da koncept notranjega trženja določa, da »je notranji trg zaposlenih $v$ smeri servilnosti in usmerjenosti h kupcu najbolje motiviran z aktivnim, $\mathrm{k}$ cilju usmerjenim pristopom, pri čemer so interno uporabljene številne aktivnosti in procesi na aktiven, trženju podoben način. Tako se notranji odnosi med ljudmi iz različnih oddelkov in procesov (zaposleni, ki imajo stik s porabnikom, zaposleni, ki opravljajo podporne funkcije, vodje skupin, nadzorniki in menedžerji) kar najbolje razvijajo in usmerjajo proti servilno naravnanemu menedžmentu in implementaciji zunanjih odnosov s porabniki in ostalimi deležniki.«

Grönroos tako dovolj holistično konceptualizira področje notranjega trženja, pri čemer mu res ne gre očitati pomanjkljivega omenjanja sodelovanja med t. i. »tržniki, zaposlenimi za polovični delovni čas, « in stržniki, zaposlenimi za polni delovni čas«. Tudi Frost in Kumar (2000, str. 359) na primer iz Grönroosovih opredelitev razbirata vlogo sodelovanja med različnimi ravnmi zaposlenih $v$ organizaciji. Ker $v$ zvezi $z$ notranjim trženjem žc ves čas poudarjamo zaposlene in na nek način tudi ravnanje $z$ njimi, pa se povsem upravičeno poraja tudi vprašanje o tem, kakšna je pri tem vloga formalne poslovne funkcije ravnanja $s$ človeškimi viri.

\section{POVEZAVA NOTRANIEGA TRŽENIA S FUNKCIJO RAVNANIA S ČLOVEŠKIMI VIRI TER IZOBRAŽEVANJEM V ORGANIZACIJI}

Notranje trženje ne sme biti samo v rokah tržnikov, ker bi bilo sicer to $v$ nasprotju s samim konceptom trženja, temelječega na odnosih (Ballantyne, 2003, str. 1243; Peck idr., 1999, str. 323). Podobno menita tudi Ahmed in Rafiq (2002, str. 62), ko pravita, da notranje trženje ne sme biti v domeni zgolj ene poslovne funkcije v organizaciji. Predstavljena stališča tako nakazujejo na to, da mora biti notranje trženje povezano $z$ različnimi funkcijami v podjetju, od katerih se verjetno zdi intuitivno najbližja ravno funkcija ravnanja s človeškimi viri. Palmer (1998, str. 178) na primer pravi, da se trženjski menedžerji v storitvenem sektorju vse bolj zavedajo dejstva, da trženjski načrti ne morejo biti izolirani od načrtov s področja ravnanja s človeškimi viri, Peckova idr. (1999, str. 319) pa se sprašujejo o tem, ali naj bo notranje trženje del trženjske funkcije ali del funkcije ravnanja s človeškimi viri.

V zvezi s tem se opredeljuje Grönroos (2001, str. 334), ko povzema nekatere avtorje in pravi, da ne gre enačiti funkcije ravnanja človeških virov $\mathrm{z}$ notranjim trženjem. Po njegovem mnenju namreč prva zagotavlja orodja, ki jih je moč uporabiti v okviru notranjega trženja, slednja pa usmeritve o tem, kako naj bodo ponujena orodja uporabljena. V okviru usmeritev je mišljen trženjski pristop, kar Ahmed in Rafiq (2002, str. 10) razumeta v Grönroosevem pojmovanju notranjega trženja. Sicer pa je potreben nadaljnji razvoj konstruktov notranjega trženja, da bi ga bilo možno bolje ločiti od podobnih konstruktov ravnanja s človeškimi viri (Caruana in Calleya, 1998, str. 113). Predstavljeno razumevanje notranjega trženja in ravnanja človeških virov tako lahko označimo kot komplementarno, saj gre iz omenjenega čutit predvsem poudarek na medfunkcijskem sodelovanju in ne tekmovanju. Kljub temu pa meja med predmetoma razprave ni jasno in enoznačno določena.

Po eni izmed definicij (Milkovich in Boudreau, 1997, str. 2) e namreč ravnane s človeškimi viri aserija povezanih odločitev, ki oblikujejo zaposlitveni odnos; njihova kakovost neposredno prispeva $k$ sposobnosti 
organizacije in zaposlenih, da dosežejo svoje cilje«. Če predstavljeno definicijo primerjamo $z$ ostalimi iz tabele 1 , potem vidimo, da gre na marsikaterem področ u za medsebo no prekrivan e. To na primer potr u e tudi Bateson (1991) (v Caruana in Calleya, 1998, str. 109), ko pravi, da notran e tržen e predstavl a elemente dobrega ravnan a šloveškimi viri. Podobno meni o tudi Ahmed, Rafiq in Saad (2003, str. 1222), ko povzema o elcmente notran ega tržcn a številnih avtor ev, kot so komuniciran e, usposabl an e, izobraževan c in informirane, motiviran e in razvo, pridobivan e, zaposlovan e in obdržan e zaposlenih; za omen ene elemente sicer pravi o, da tradicionalno pripada o funkci i ravnan a $s$ človeškimi viri.

$\mathrm{V}$ skladu $s$ predstavl enim povzemamo razmišl an e Grönroosa (2001, str. 333). Pravi, da tako vrhn i menedžment kot seveda tudi tržen e in oddelek za ravnan e s človeškimi viri prispeva o $\mathrm{k}$ uspešni implementaci i notran ega tržen a. To lahko stori o samo s sodelovan em $z$ vsemi ostalimi oddelki, $k$ er so zaposleni stržniki s polovičnim delovnim časom«. Notran e tržen e tako funkcionira kot holistično upravljan proces, ki integrira različne funkci e $v$ organizaci $i \mathrm{v}$ dveh smerch. Zagotavl a, da vsi zaposleni v organizaci $\mathrm{i}$ razume o ter okuša o posel in n egove raznolike aktivnosti, namembnosti in procese $v$ luči okol a, ki podpira usmer enost $h$ kupcu ter zagotavl a, da so vsi zaposleni pripravl eni in motivirani v smeri servilnosti (prav tam). Gre tore za način razmišljanja, za filozofijo upravljanja, ki po mnen u Vareya in Lewiseve (1999, str. 940) v skontekstu notranjih odnosov predstavlja integrativni proces sistema za vzgajanje pozitivnih medsebojnih odnosov v razvojni smeri kooperativne klime in dosežkov.«

\section{VLOGA IN POMEN PRENAŠANJA PRISTOJNOSTI NA PODREJENE}

Prenos pristo nosti na podre ene ${ }^{4}$ pri tem vel a za kl učno komponento notran ega tržen a (Papasolomou-Doukakis in Kitchen, 2004, str. 428; Ahmed in Rafiq, 2002, str. 70, Nickels in Wood, 1997, str. 46). Klima prenosa pristo nosti na podre ene e lahko kreirana na ravni vrhn ega menedžmenta in e prenesena na vse ravni organizaci e. Številni tržniki se tako premika o s tradicionalnih organizaci skih struktur, k er zaposleni sledi o navodilom menedžmenta, $\mathrm{k}$ obrn enim, ravno nasprotnim organizaci skim strukturam, v katerih ima o zaposleni pooblastila za odločan e, menedžment pa ih pri tem podpira (Nickels in Wood, 1997, str. 46-47). Tovrstni zasuk prikazu e slika 1

Glavni namen prenosa pristo nosti na podreene e v tem, da izbol ša učinek kontaktnega in podpornega oseb a, sa $v$ primeru pravilne in korektne implementaci e omen ene metode lahko občutno prispeva $\mathrm{k}$ zadovol stvu zaposlenih, kar ima za posledico bol ši stik s porabniki v t. i. »trenutkih resnice« (Grönroos, 2001, str. 346). Gre tore za zasledovan e dveh

Slika 1: Tradicionalna organizacijska struktura (levo) in t. i. obrnjena organizacijska strukura (desno)

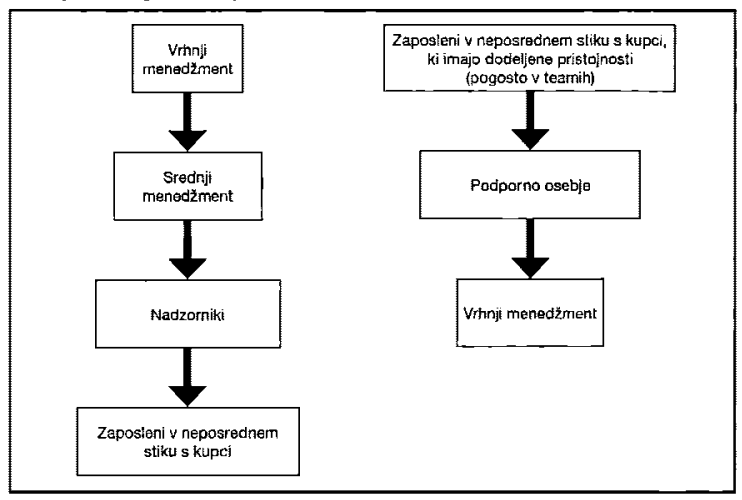

Vir: Nickels in Wood, 1997, str. 47 
Pomembnejši razlog, ki govori v prid potrebi po uvajanju prenosa pristojnosti na podrejene, je karakteristika simultanosti proizvodnje in porabe storitev (Ahmed in Rafiq, 2002, str. 70), kar po Palmerju (1998, str. 12) poimenujemo neločljivost. Zavedati se je namreč potrebno dejstva, da ima prodajno oziroma kontaktno osebje zaradi tega nemalokrat lahko kopico težav, saj se vsakodnevno srečuje z zelo različnimi kupci, ki imajo zelo različen nakupovalni slog. Zato je določena vrsta prostosti lahko občutno pomagalo $\mathrm{k}$ temu, da lahko tudi prodajno oziroma kontaktno osebje svoje reakcije in dejanja prilagaja različnim slogom kupcev. Nenazadnje, zadovoljstvo kupcev (tako notranjih kot zunanjih) je verjetno pomembnejše kot pa strogo upoštevanje togih pravil (Papasolomou-Doukakis in Kitchen, 2004, str. 441). Prav tako je potrebno upoštevati spoznanje Bitnerjeve, Boomsa in Mohra (1997, str. 150) o tem, da je kontaktno osebje ključni vir informacij o kupcihs. S prenosom pristojnosti se tako lahko glede na novo definirano vlogo kontaktnega osebja tovrstni vir informacij okrepi.

ciljev - izboljšanja motivacije in produktivnosti zaposlenih ter posledično izboljšanja storitve za kupca (Ahmed in Rafiq, 2002, str. 72). Peckova idr. (1999, str. 322) ločijo več vrst prenosa pristojnosti na podrejene - od popolne, pri kateri imajo zaposleni popolno moč, da naredijo vse, kar je v prid zadovoljstvu kupca, do milejših oblik, kjer zaposleni lahko pomagajo zgolj z namigi, vse ostale odločitve pa ostajajo v rokah nadrejenih.

Pri tem se je seveda potrebno zavedati neizbežnega dejstva, da omenjena metoda ni primerna za vse vrste delovnih mest ter za vse zaposlene (Ahmed in Rafiq, 2002, str. 70; Berry in Parasuraman, 1991, str. 165), in naloga menedžmenta je, da oceni primernost omenjene metode $v$ različnih okoliščinah. $\mathrm{V}$ nekaterih primerih je tako pri uvajanju tovrstne kulture $v$ podjetju občutiti strah $s$ strani srednje ravni menedžmenta, ki se čuti ogroženega, spet $v$ drugih pa so zaposleni enostavno nepripravljeni sprejeti nove odgovornosti, za katere raje menijo, da morajo biti $v$ pristojnosti nadrejenih (Peck idr. 1999, str. 322; Grönroos, 2001, str. 348). 


\section{AKTIVNOSTI NOTRANJEGA TRŽENIA}

Pri omenjanju aktivnosti notranjega trženja so najjasnejši in najeksplicitnejši Grönroos (2001, str. 340-344) ter Ahmed, Rafiq in Saad (2003, str. 1223), ko ponujajo nabor nekaterih aktivnosti. Grönroos (2001, str. 340) pri tem sicer tudi povsem jasno pove, da ne obstaja nek dokončen seznam predlaganih aktivnosti, s čimer se strinja tudi Piercy (1995, str. 37), ko pravi, da je fraza notranjega trženja deIežna številnih različnih pomenov. Grönroos (2001, str. 340-344) ter Ahmed, Rafiq in Saad (2003, str. 1223) tako omenjajo aktivnosti, kot so usposabljanje, podpora menedžmenta in notranji dialog, notranja množična komunikacija in informacijska podpora, vloga funkcije ravnanja človeških virov $v$ smislu rekrutacije in zadržanja ustreznih kandidatov, sugestije zaposicnih pri zunanji komunikaciji s trgom, razvojni sistemi in tehnološka podpora, notranja pomoč pri reševanju reklamacij, vloga trženjskih raziskav v smislu delovanja znotraj organizacije, strateško nagrajevanje, sama organizacijska struktura, fizično okolje, medfunkcijska koordinacija, sistemi spodbujevanja in operativno procesne spremembe.

\section{SKLEPNA MISEL}

Vidimo lahko, da gre za mnogotere aktivnosti, pri čemer, kot smo že omenili, seznam sploh ni nujno dokončen, kar lahko v smislu operacionalizacije koncepta deluje tudi kot pomanjkljivost; za takšno stanje bi lahko nekdo uporabil izraz, da gre torej za nek vseobsegajoči termin. Vendar to ni nujno tudi slabo, saj je vsaka organizacija skupek posebnosti, ki poslovne cilje dosega na sebi lasten način. Zato je morda tudi bolje, da ne obstaja neka enotna praksa $\vee$ zvezi $z$ uvajanjem elementov notranjega trženja, saj je sama ideja omenjenega tako mnogo lažje prilagodljiva času in prostoru, $v$ katerem naj se koncept nahaja. Kot je bilo namreč že omenjeno, je koncept notranjega trženja slabše sprejet v svetu menedžmenta ravno zaradi svoje naprednosti, zato bi bilo verjetno nesmiselno vztrajati pri rigoroznih pravilih uvajanja nečesa takšnega. Tudi Grönroos (2001, str. 332) pri tem zasleduje zelo svobodomiselno držo, ko pravi, da je morda poimenovanje notranje trženje celo neustrezno, saj so ljudje, ki se jih to najbolj tiče, torej t. i. wtržniki za polovični delovni čas", lahko izrazito nenaklonjeni konceptom, ki vsebujejo besedo trženje. Tako je seveda tudi v domeni vsake organizacijc, da izbere svoji lastni organizacijski kulturi ustrezno poimenovanje koncepta, predstavljenega $\mathrm{v}$ pričujoči razpravi; podobno seveda velja tudi za pot implementacije omenjenega.

\section{LITERATURA}

Ahmad, R., Buttle, F. (2002). Customer retention management: a reflection of theory and practice. Marketing Intelligence and Planning, 20, str. 149-161.

Ahmed, P. K., Rafiq, M. (2002). Internal Marketing. Tools and Concepts for Customer-Focused Management. New York: Butterworth Heinemann.

Ahmed, P. K., Rafiq, M., Saad, M. N. (2003). Internal marketing and the mediating role of competencies. European Journal of Markcting, 37, str. 1221-1241.

Al-Khayyat, M. R., Elgamal, A. M. (1997). A macro model of training and development: validation. Journal of European Industrial Training, 21, str. 87-101.

Ballantyne, D. (2000). Internal relationship marketing: a strategy for knowledge renewal. Internal Journal of Bank Marketing, 18, str. 274-286.

Ballantyne, D. (2003). A relationship-mediated theory of internal-marketing. European Journal of Marketing, 37, str. 1242-1260.

Berry, L. L. (2000). Relationship Marketing of Services. V Sheth, N., Jagdish Parvatiyar Atul (ur.), Handbook of Relationship Marketing. London: Sage Publications, Inc., str. 149-170.

Berry L. L., Parasuraman A. (1991). Marketing services. Competing through quality. New York: The Free Press.

Bitner, Jo M., Booms, H. B., Mohr, A. L. (1997). Critical Service Encounters: The Employee's Viewpoint. V Gabbott, M., Hogg, G. (ur.), Contemporary Services Marketing Management. London: The Dryden Press, str, $149-170$.

Broady-Preston, J., Stcel, L. (2002). Internal marketing 
strategies in LIS: a strategic management perspective. Library Management, 23, str. 294-301.

Caruana, A., Calleya, P. (1998). The effect of internal marketing on organisational commitment among retail bank managers. International Journal of Bank Management, 16, str. 108-116.

Daft, L. R., Marcic, D. (2001). Understanding Management. 3. izdaja. Singapore: South-Western Thomson Learning.

Davis, R. V. T. (2001). Integrating internal marketing with participative management. Management Decision, 39, str. 12!-130.

Drucker, F. P. (1992). Don't Change Corporate Culture - Use It! V Lovelock C. J. (ur.), Managing Services. Marketing, Operations, And Human Resources. 2. izdaja. Str. 406-408. London: Prentice Hall International, Inc.

Flipo, J, P. (1986). Service Firms: Interdependence of External and Internal Marketing Strategies. European Journal of Marketing, 20, str. 5-J4.

Foster, D. B., Cadogan, W. J. (2000). Relationship selling and customer loyalty: an empirical investigation. Marketing Intelligence and Planning, 18, str. 185-199.

Frost, A. F., Kumar, M. (2000). INTSERVQUAL - an internal adaptation of the GAP model in a large service organisation. Journal of Services Marketing, 14, str. 358-377.

Grönroos, C. (2001). Service Management and Marketing. Ncw York : John Wiley and Sons, Ltd.

Judd, C. V. (2003). Achieving a customer orientation using "people power" - the "5 $5^{\text {th }} \mathrm{P}$ ". European Journal of Marketing, 37, str. 1301-1313.

Kang, G., James, J., Alexandris, K. (2002). Measurement of internal service quality: application of the SERVQUAL battery to internal service quality. Managing Service Quality, 12, str. 278-291.

Kotler, P. (1972). A Generic Concept of Marketing. Journal of Marketing, 36, str. 46-54.

Lings, N. I, (2000). Internal marketing and supply chain management. Journal of Services Marketing, 14, str. $27-43$.

Marshall, W. G., Baker, J., Finn, W. D. (1998). Exploring internal service quality. Journal of Business and Industrial Marketing, 13, str. 381-392.

Milkovich, T. G., Boudreau, W. J. (1997). Human Resource Management. 8. izdaja. New York: Irwin/Mcgraw-Hill.

Nickels, G. W., Wood, B. M. (1997). Marketing. Relationships, Quality, Value. New York: Worth Publishers.

Palmer, A. (1998). Principles of Services Marketing. 2. izdaja. London: McGraw-Hill Publishing Company. Papasolomou-Doukakis, I., Kitchen, J. P. (2004). Internal marketing in UK banks: conceptual legitimacy or window dressing? The International Journal of Bank
Marketing, 22, str. 421-452.

Peck, H., Paync, A., Christopher, M., Clark, M. (1999). Relationship Marketing. Strategy and implementation. Oxford: Butterworth-Heinemann.

Piercy, F. N. (1995): Customer satisfaction and the internal market. Journal of Marketing Practice: Applied Marketing Science, 1, str. 22-44.

Rafiq, M., $\Lambda$ hmed, P. K. (2000). Advances in the internal marketing concept: definition, synthesis and extension. Journal of Services Marketing, 14, str. 449-462.

Sargeant, A., Asif, S. (1998). The strategic application of internal marketing - an investigation of UK banking. International Journal of Bank Markesing, 16, str. 66-79.

Varey, 1. R. (1995). Internal marketing: a review and some interdisciplinary research challenges. International Journal of Service Industry Management, 6, str. 40-63.

Varey, J. R., Lewis, R. B. (1999). A broadened conception of internal marketing. European Journal of Marketing, 33, str. 926-944.

'Grönroos (2001, str: 56) v tem primeru povzema izraz, po Gummessonu (1999, str. 8-9) in tako ločuje med t. i. stržniki s polnim delovnim casoma in "ržnikis polovičnim delovnim časoma (ang. full-rime marketers in part-time narketers).

${ }^{2}$ Berry (2000, st: 162) ter Peckova id: (1999. str. 314) na primer ugotavljajo, da imajo zaposleni, ki so allje časa vorganizaciji, več znanja o sami naravi poslovanja in več priložnosti za razvitje zaupanja in domac̆nosti s porabnikom, so boljši v razvijanju odnosa z njim, bolje razumejo njegove potrebe in se bolje znajdejo v situacijah z nezadovoljnimi kupci. Almad in Butle (2002, str. 158) pri tem opozarjala, da je zadržanje zaposlenih per se lakko kontraproduktivno, če se sposobnosti in izktı̌nje zadržanih ne ujemajo s strategijo organizacije.

${ }^{3} V$ zvezi s tovrstnim pojmovanjem notranjega trženja nekateri avtorji (Kang, James in Alexandris (2002): Frost in Kumar (2000) ter Marshall, Baker in Finn (1998)) uvajajo pojem norranje kakovosti storitev. Skupni imenovalec tovrstnega razmišljanja je v fem, da mora opravljeno delo, ki je razporejeno med različnini oddelki znotraj neke organizacije, kakovostno zadovoljevati potrebe in zahteve vseh vpletenih v verigi. Tako Marshall, Baker in Finn (1998, str. 387-388) za potrebe nabavne službe identificirajo sedem dimenzij (dimenzija uslužnosti, prijaznosti in pomembnosti, dimenzija dostave vrednosti, dimenzija reševanja problema, dimenzija procesa naročanja, dimenzija natančnosti, dimenzija upravljanja dobave ter dimenzija 
"brez presenečenj «). Kang. James in Alexandris (2002) ter Frost in Kumar (2000) pa se pri svojem delu opirajo na znani model SERVQUAL, ki je sicer namenjen merjenju kakovosti storitev za končnega kupca. Z ustrezno adaptacijo jo skušajo priredifi za potrebe merjenja notranje kakovosti, pri tem pa prihajajo do podobnih zaključkov kot izvirna šrudija. Kang. James in Alexandris (2002, str. 288) tako lgotavljajo, da sta pri notranji kakovosti najpomembnejši dimenziji zanesljivosti in odzivnosti, Frost in Kumar (2000, str. 374) pa podobno ugotavljata, da je najpomembnejša dimenzija odzivnost. Sicer je po mnenju Peckove id: (1999, str. 316) notranja kakovost pomembna tudi z vidika izholjšave odnosov s končnimi kupci.

- Po Dafiu in Marcicu (2001, str. 241) je prenos pristojnosti na podrejene pojmovan kot „delegiranje pooblastil za odločanje, svobode, znanja, neodvisnosii in sposobnosti podrejenim«.

'Avtorji (Bitner, Booms in Bohm, 1997, str. 164) sicer opozarjajo na 10 , da je potrebno posredovane informacije s strani kontaktnega osebja razumeti $z$ določeno mero previdnosti, saj gre včasih za netočne ocene o pričakovanjih in zadovoljstvu kupca.

${ }^{6}$ Proces $v$ nastajanjt storitve, ki nastane zaradi neločljivosti proizvodnje in potrošnje med kupcem in prodajalcem, Grönroos (2007, str: 72) po Normannu (1992) poimenuje trenutki resnice (omoments of truhin). 